archives-ouvertes

\title{
Symbiosis disruption in the olive fruit fly, Bactrocera oleae (Rossi), as a potential tool for sustainable control
}

\author{
Martina Sinno, Annie Bezier, Francesco Vinale, David Giron, Stefania
}

Laudonia, Antonio Garonna, Francesco Pennacchio

\section{To cite this version:}

Martina Sinno, Annie Bezier, Francesco Vinale, David Giron, Stefania Laudonia, et al.. Symbiosis disruption in the olive fruit fly, Bactrocera oleae (Rossi), as a potential tool for sustainable control. Pest Management Science, Wiley, In press, 76, pp.3199 - 3207. 10.1002/ps.5875 . hal-02637937

\section{HAL Id: hal-02637937 \\ https://hal.archives-ouvertes.fr/hal-02637937}

Submitted on 18 Jan 2021

HAL is a multi-disciplinary open access archive for the deposit and dissemination of scientific research documents, whether they are published or not. The documents may come from teaching and research institutions in France or abroad, or from public or private research centers.
L'archive ouverte pluridisciplinaire HAL, est destinée au dépôt et à la diffusion de documents scientifiques de niveau recherche, publiés ou non, émanant des établissements d'enseignement et de recherche français ou étrangers, des laboratoires publics ou privés. 


\title{
Symbiosis disruption in the olive fruit fly, Bactrocera oleae (Rossi), as a potential tool for sustainable control
}

\author{
Martina Sinno, ${ }^{a^{*} \odot}$ Annie Bézier, ${ }^{b}$ Francesco Vinale, ${ }^{c, d}$ David Giron, ${ }^{b}$ \\ Stefania Laudonia, ${ }^{a}$ Antonio P. Garonna ${ }^{a}$ and Francesco Pennacchio ${ }^{\mathrm{a}}$
}

\begin{abstract}
BACKGROUND: The oljye fruit fly Bactrocera oleae (Rossi) (OLF) is a major agricyltural pest, whose control primarily relies on the symbiotic bacterium of OLF, 'Candidatus Erwinia dacicola', is essential for successful larval development in unripe olive fruits. Therefore, targeting this endosymbiont with antimicrobial compounds may result in OLF fitness reduction and may exert control on natural populations of OLF.

RESULTS: Here, we evaluate the impact of compounds with antimicrobial activity on the OLF endosymbiont. Copper oxychloride (CO) and the fungal metabolite viridiol (Vi), produced by Trichoderma spp., were used. Laboratory bioassays were carried out to assess the effect of oral administration of these compounds on OLF fitness and molecular analyses (quantitative polymerase chain reaction) were conducted to measure the load of OLF-associated microorganisms in treated flies.

$\mathrm{CO}$ and Vi were both able to disrupt the symbiotic association between OLF and its symbiotic bacteria, determining a significant reduction in the endosymbiont and gut microbiota load as well as a decrease in OLF fitness. CO had a direct negative effect on OLF adults. Conversely, exposure to Vi significantly undermined larval development of the treated female's progeny but did not show any toxicity in $\mathrm{LLF}$ adults.
\end{abstract}

CONCLUSIONS: These results provide new insights into the symbiotic control of OLF and pave the way for the development of more sustainable strategies of pest control based on the use of natural compounds with antimicrobial activity.

Supporting information may be found in the online version of this article.

\section{INTRODUCTION}

The olive fruit fly Bactrocera oleae Rossi (OLF) causes severe yield losses and reduced quality of olives and derived products, ${ }^{1-3}$ with an estimated $15 \%$ reduction in world production per year. ${ }^{4}$ During the past 40 years, control strategies for $B$. oleae have been based on the wide use of chemical insecticides, both as bait and as cover spray. ${ }^{5-8}$ However, insecticide misuse has promoted the development of resistance, ${ }^{6,7,9-13}$ with a negative impact on non-target arthropods ${ }^{14}$ and olive oil quality. ${ }^{15}$ Therefore, sustainable control strategies for OLF are highly desirable, ${ }^{16,17}$ and in line with the inspiring principles of EU Directive 128/2009 on the sustainable use of pesticides.

Currently available alternatives to chemical pesticides are the attract-and-kill method, mass trapping devices, and use of biological control agents (BCA) or sterile insect techniques (SIT), with effects that are not always satisfactory in all instances. ${ }^{16,18-26}$ Unfortunately, olive cultivars showing resistance/tolerance to OLF are not available, ${ }^{27}$ even though this could be a promising area of research. ${ }^{28-30}$

An alternative new opportunity for pest control relies on disruption of insect symbiosis, also known as 'symbiotic control'. ${ }^{31-34}$ Insect life and evolution are strongly influenced by microorganisms associated with the insect. ${ }^{35,36}$ The insect is, therefore, a metaorganism (or holobiont) controlled by a complex network of interactions with its associated microbiota, which can be manipulated and/or suppressed by targeting either the insect or the microbial component. ${ }^{31,32,35,37-39}$ The symbiotic control of insect pests has recently been reviewed by Arora and Douglas. ${ }^{33}$ Among the different options that can be pursued, disruption of vertical transmission (mother to offspring) of an obligate endosymbiont required for nutrition, insect growth, reproduction or survival, seems to be an amenable target.

Implementation of symbiotic control strategies can be fostered by the discovery of novel natural molecules with antimicrobial

\footnotetext{
Correspondence to: M Sinno, Department of Agricultural Sciences, University of Naples Federico II, 80055 Portici (NA), Italy, E-mail: martinasinno@hotmail.it

a Department of Agricultural Sciences, University of Naples Federico II, Portici (NA), Italy

b Research Institute for the Biology of Insect (IRBI) - UMR 7261 CNRS/Université de Tours, Tours, France

c Department of Veterinary Medicine and Animal Production, University of Naples Federico II, Naples, Italy
}

d CNR Institute for Sustainable Plant Protection, Portici (NA), Italy 
activity. This appears to be a promising research area, as indicated by the successful use of antimicrobial peptides against the primary endosymbiont of Sitophilus sp. (Schoenherr) or Buchnera, the bacterial symbiont of the pea aphid (Acyrthosiphon pisum Harris) and the green peach aphid (Myzus persicae Sulzer). ${ }^{40-42}$

Since the beginning of the last century, $B$. oleae has been known to harbor endosymbiotic bacteria. ${ }^{43} \mathrm{~A}$ study by Capuzzo et al. confirmed that a single, non-culturable bacterial species, 'Candidatus Erwinia dacicola' (Enterobacteriaceae: Gammaproteobacteria), represents nearly the entire symbiotic population associated with OLF. ${ }^{44}$ Constant association of this symbiont with all life stages of different widespread OLF populations, ${ }^{44-50}$ its vertical transmission to offspring, ${ }^{46}$ and its specific localization, within both larvae and adults, ${ }^{46,47}$ collectively indicate a highly specific and longterm symbiotic relationship. $47,51,52$

During mass-rearing, the standard artificial diet routinely used contains antibiotics that block the natural transmission of endosymbionts, which are replaced by environmental bacteria. In these conditions, both the adult and larval stages show a remarkable decrease in fitness. ${ }^{48,53,54}$ To alleviate this, the development of antibiotic-free and probiotic-supplemented diets, as well as the horizontal transfer of the endosymbiont from wild flies to laboratory-reared strains have been successfully pursued. ${ }^{55-58}$

Recent studies suggested that ' $\mathrm{C}$. Erwinia dacicola' is able to use many different nitrogenous sources present in the diet of wild OLF populations to synthesize essential amino acids, which are then made available to the host to complement its poor nutritional substrate, to support both development and reproduction. ${ }^{59-61}$ Furthermore, a capacity to influence the oviposition behavior of its insect host has recently been demonstrated. ${ }^{62}$

Unlike most fruit fly species, which lay eggs in ripe and nutritionally suitable fruits, ${ }^{63-67}$ OLF larval stages can also develop in unripe olives, exploiting a broader temporal window for multiple generations on a single host. ${ }^{68,69}$ Unripe fruits are generally resistant to herbivores and pathogen attack thanks to the high secondary metabolite content, which has antimicrobial, antinutritive and toxic effects. ${ }^{70,71}$ The unripe fruit of Olea europaea (L.) is no exception; in fact, it contains several secondary metabolites, the most abundant of which is oleuropein, a bitter phenolic glycoside that can contribute up to $14 \%$ of fruit dry weight. ${ }^{29,71,72}$ Ben-Yosef et al. have lately shed light on the role of bacterial symbionts in overcoming the nutritional constraints imposed by phenolic compounds present in the unripe olive fruits. ${ }^{53}$ In fact, whereas symbiotic larvae were able to develop in unripe olive fruits, their aposymbiotic counterparts could not reach the pupal stage, demonstrating that ' $\mathrm{Ca}$. Erwinia dacicola' is essential for the development of $B$. oleae larvae in unripe olive fruits. ${ }^{53,73}$

Thus, 'Ca. Erwinia dacicola' is thought to play a key role in OLF larval stage survival, ${ }^{53,59,60,73}$ and disruption of this symbiotic association can offer new opportunities for pest control. A recent study by Bigiotti et al., showed fitness reduction in adult flies with reduced symbiont loads in the esophageal bulb as a consequence of exposure to antimicrobial compounds, such as copper and propolis. ${ }^{74}$ However, no data are available on the transgenerational effects of antimicrobial treatments, and, thus, on their potential to limit larval development in unripe olive fruits, which should be the major goal of a symbiotic control strategy.

Here, we contribute to this research by investigating insecticide activity on OLF adult and larval stages, and the concurrent impact on its microbiota, exerted by antimicrobial compounds of differing origin. We focused our attention on viridiol (Vi), a secondary metabolite biosynthesized by beneficial fungi belonging to the genus Trichoderma (Hendrik). ${ }^{75-78} \mathrm{Vi}$ is a steroid-like molecule with broad antimicrobial activity both in vivo and in vitro; it is produced by T. virens (Mill), T. viride (Pers.), T. hamatum (Bonorden), Hypocrea virens (Chaverri) and certain Gliocladium (Corda) species. ${ }^{79-81}$ Trichoderma is one of the most studied fungal biocontrol agents and its activity is also related to the variety of metabolites they produce. These metabolites have been found to directly inhibit pathogens, increase disease resistance, and also enhance plant growth in a field experiment. ${ }^{82}$

We also focused on copper oxychloride (CO), which is widely used in olive groves for disease control. Field observations of reduced OLF infestations associated with the use of $\mathrm{CO}$ led to the hypothesis that this compound may act as a symbioticide, ${ }^{83-91}$ which was corroborated by a recent laboratory study. ${ }^{74}$ A remarkable negative effect of copper treatments on larval growth has been reported, ${ }^{90}$ along with a deterrent effect on OLF oviposition. ${ }^{91}$ Furthermore, CO was found to be moderately toxic when orally administered both to adults and larval stages of several insect species, including Diptera. ${ }^{92-95}$ Here, we try to assess if these negative effects of CO on OLF can be due in part to its impact on associated microbiota.

Laboratory bioassays were carried out on wild populations to assess the suitability of these compounds for OLF symbiotic control. We recorded the mortality and fecundity of adult flies and larval development of their progeny in unripe olive fruits. To measure any concurrent change in the associated microbiota, we also estimated the endosymbiont load in the esophageal bulb and the midgut, as well as the overall microbiota resident in the midgut using a quantitative polymerase chain reaction (qPCR) approach.

\section{MATERIALS AND METHODS}

\subsection{Sampling, origin and maintenance of $B$. oleae wild population}

Olives were collected from trees in a pesticide-free experimental field of Olea europaea at the Department of Agricultural Sciences, University of Naples Federico II (Portici, NA, Italy). Infested olives were collected weekly, from September to December, in 2015 and 2016, placed in plastic trays, bottom lined with paper, and incubated in a controlled rearing room $\left(24 \pm 2{ }^{\circ} \mathrm{C}, 60 \pm 10 \%\right.$ relative humidity, and 12:12 h light/dark photoperiod). Mature larvae and puparia were collected daily and caged; emerged adults were sexed and maintained separately in groups of 30 flies, using cylindrical cages (20 cm diameter, $15 \mathrm{~cm}$ height).

\subsection{Viridiol production and purification}

For Vi production, $T$. virens strain GV41, obtained from actively growing margins of potato dextrose agar (PDA; Hi Media, Mumbai, India) cultures, was used. The fungal strain was maintained on PDA slants at room temperature, and subcultured every 2 months. Two 7-mm diameter plugs of the abovementioned strain were inoculated into $5 \mathrm{~L}$ conical flasks containing $1 \mathrm{~L}$ of sterile potato dextrose broth (PDB; Hi Media). Stationary cultures were incubated for 31 days at $25^{\circ} \mathrm{C}$ and then filtered under vacuum through filter paper (Whatman No. 4, Brentford, UK). Subsequently, the filtrates were stored at $2{ }^{\circ} \mathrm{C}$ for $24 \mathrm{~h}$. Two liters of the filtered culture broth of strain GV41 were extracted with ethyl acetate (EtOAc). The combined organic fractions were dried $\left(\mathrm{Na}_{2} \mathrm{SO}_{4}\right)$ and evaporated under reduced pressure at $35^{\circ} \mathrm{C}$. The recovered yellow residue was then subjected to column chromatography (Si gel; $50 \mathrm{~g}$ ), eluted with a gradient of EtOAc/petroleum ether (from 8:2 to 10:0). Similar thin layer chromatography (TLC) profiles fractions were combined and 
subsequently purified with preparative TLC separation (Si gel; EtOAc/petroleum ether, 6:4) or silica gel flash chromatography (EtOAc/petroleum ether, 8:2 to 10:0). Preparative silica gel TLC of fractions 2, 3 and 4 yielded $6 \mathrm{mg}$ of Vi. Analysis of the mass spectrometry (MS) and nuclear magnetic resonance (NMR) spectra finally revealed the expected signals previously described for such compound, confirming the purity of the obtained product. ${ }^{79}$

\subsection{Bioassays}

\subsubsection{Adult survival}

The basic diet for OLF adults was sucrose $(0.5 \mathrm{~g})$ solubilized in water $(200 \mu \mathrm{L})$, in which were dissolved the following experimental compounds: $\mathrm{CO}(0.5 \%, 0.1 \%$ and $0.02 \% \mathrm{w} / \mathrm{w}$ sucrose) and $\mathrm{Vi}$ ( $0.5 \%$ and $0.1 \% \mathrm{w} / \mathrm{w}$ sucrose). As negative control, the sucrose diet completed with the antibiotic piperacillin $\left(100 \mu \mathrm{g} \mathrm{mL}^{-1}\right.$; SigmaAldrich, S. Louis, MO, USA), abbreviated to 'antibiotic' in this study, was used to clear the endosymbiotic bacteria from the fly's gut, ${ }^{59,60}$ while plain diet (sucrose only) acted as a positive control. In all cases, the diet was dried in an oven at $50{ }^{\circ} \mathrm{C}$ for $3 \mathrm{~h}$ and offered in a solid form to the experimental insects.

Newly emerged adults were sexed then kept in groups of 30 individuals for each sex, with ad libitum access to one of the different experimental diets; for each diet/treatment three groups of females and three groups of males where used, giving a total of 1260 experimental flies. From the onset of the experiment to sexual maturity, which was attained after 14 days, ${ }^{96}$ the percentage of surviving flies was recorded daily along with the diet consumption per fly/day. This was obtained by calculating the difference between the weight of the diet on day 1 and that recorded on day 14 , which was divided by the average number of flies found alive every day.

\subsubsection{Adult reproduction}

On the 14th day, mature adults (at least 15 females and 15 males) were allowed to mate. Non-infested and unripe olive fruits were offered to mated females for the oviposition (one olive/female) The olives in the cage were replaced after 3 days to assess any time-related change in reproductive activity. One half of the olives from these two groups was sectioned to assess the number of laid eggs per female, while the second half was incubated for 3-4 weeks to allow larval development.

At the end of the oviposition tests, all treated adults were stored at $-80^{\circ} \mathrm{C}$, until further processing.

\subsubsection{Larval development}

The number of eggs laid by reared females that completed development and gave rise to adults was scored daily. The number of offspring/female was used to assess the successful development in unripe olives, which requires the presence of primary endosymbionts. $^{53}$

\subsection{DNA extraction}

Frozen flies were surface-sterilized by vortexing for $15 \mathrm{~s}$ in a $1 \%$ sodium hypochlorite $0.1 \%$ Triton $\mathrm{X}$ solution, rinsed twice with distilled water and then dissected under sterile conditions in a laminar flow hood to isolate the head and the abdomen, where the esophageal bulb and midgut reside, respectively.

After dissection, pooled samples of four heads and four abdomens were separately used for DNA extraction to assess the level of bacterial load within the esophageal bulb and the midgut. DNA was extracted using a PureLink ${ }^{\circledast}$ Genomic DNA Mini Kit (SigmaAldrich), following the manufacturer's instructions. The quality and concentration of the extracted DNA were evaluated using Varioskan (Thermo Fisher Scientific, Finland) and samples with a $260 / 280 \mathrm{~nm}$ ratio $<1.6$ and $230 / 260 \mathrm{~nm}$ ratio $<1.5$ were discarded. All the remaining DNA samples were stored at $-80^{\circ} \mathrm{C}$ until further processing.

\subsection{Quantification of the endosymbiotic bacterial titer by qPCR}

The amplification of ' $\mathrm{C}$. Erwinia dacicola' $16 \mathrm{~S}$ rDNA region was obtained with primers EdEnRev and EdF1. ${ }^{47,48}$ These primers were previously validated in a study on the relative abundance of ' $\mathrm{C} a$. Erwinia dacicola' across life stages of $B$. oleae. ${ }^{48}$ Even though the specificity of these primers was recently questioned, ${ }^{58}$ it did not significantly affect the current study because the esophageal bulb is colonized almost exclusively by the primary endosymbiont, ${ }^{44,61}$ and the gut environment of the experimental population was also predominantly colonized by the primary endosymbiont (see Fig. S1).

Moreover, for midgut samples only, total bacterial load was assessed using a pair of primers, designed with Primer Express software (Thermo Fisher Scientific), within the $16 \mathrm{~S}$ rDNA region shared by all bacteria. ${ }^{97}$ Of the three tested couples of candidate primers, only the most efficient, 16 SuniF and 16 SuniR, was used for further analyses.

To normalize data, different $B$. oleae housekeeping genes were used for the two body parts. $\beta$-actin gene was used for data normalization in the esophageal bulb samples and glyceraldehyde 3-phosphate dehydrogenase (GAPDH) gene was used for data normalization in midgut samples, according to the study of Sagri et al. ${ }^{91}$ Amplification of a portion of the $\beta$-actin gene was obtained with a pair of primers designed with Primer Express. Three pairs of primers were designed, and their efficiency was tested. The most efficient pair, Act2F and Act2R, was chosen. Amplification of a portion of the gapdh gene was obtained with the pair of primers GapF and GapR. ${ }^{98}$ All primers are reported in Table 1.

Quantitative PCR experiments were carried out with $S Y_{B R}{ }^{\circledast}$ Green PCR Master Mix (Thermo Fisher Scientific, Lithuania) in a $13 \mu \mathrm{L}$ total reaction volume, containing $3 \mu \mathrm{L}$ of diluted genomic DNA, $6.5 \mu \mathrm{L}$ of Master Mix and a solution of primers with a final concentration of $300 \mathrm{~nm}$. The amplification procedure used by Estes et al. was tested and adapted. ${ }^{48}$ The experiments were performed with a StepOnePlus Real-Time PCR System (Applied Biosystems, Foster City, CA, USA) as follows: $95^{\circ} \mathrm{C}$ for $10 \mathrm{~min}$, followed by 40 cycles of $95{ }^{\circ} \mathrm{C}$ for $15 \mathrm{~s}, 60^{\circ} \mathrm{C}$ for $1 \mathrm{~min}$. Reactions were followed by a quality control melting curve and terminated by cooling.

For quantification, standard curves were generated using purified amplicons of each selected target, produced with the abovementioned primers, as a template. First, classic PCR was performed with DreamTaq PCR Master Mix (Thermo Fisher Scientific) in a total volume of $50 \mu \mathrm{L}$, using $3 \mu \mathrm{L}$ of genomic DNA extracted from the control samples and $2 \mu \mathrm{L}$ of primers $(10 \mathrm{~mm}$ each). The following conditions were used for the PCR: initial denaturation at $95^{\circ} \mathrm{C}, 2 \mathrm{~min} ; 35$ cycles of denaturation at $95^{\circ} \mathrm{C}$ for $30 \mathrm{~s}$; annealing at $60{ }^{\circ} \mathrm{C}$ for $30 \mathrm{~s}$ and extension at $72{ }^{\circ} \mathrm{C}$ for $60 \mathrm{~s}$; final extension at $72{ }^{\circ} \mathrm{C}$ for $10 \mathrm{~min}$. PCR products were separated by electrophoresis on a $1.2 \%$ agarose gel and the expected bands were successively excised from the gel and purified with QIAquick Gel Extraction Kit (Qiagen, Hileden, Germany), according to the manufacturer's instructions. The concentration of purified amplicons was determined using the Qubit 2.0 Fluorometer (Life Technologies, Singapore). 
Table 1. List of the primers used in molecular analyses

\begin{tabular}{|c|c|c|}
\hline Target genes & Primers & Amplicon length $(b p)$ \\
\hline \multirow[t]{2}{*}{ 'Candidatus Erwinia dacicola' 16S rDNA } & EdF1: 5'-CTAATACCGCATAACGTCTTCG-3' & 90 \\
\hline & EdEnRev: 5'-CCACCTACTAGCTAATCCC-3' & \\
\hline \multirow[t]{2}{*}{ Bacteria universal segment $16 \mathrm{~S}$ rDNA } & 16SuniF: $5^{\prime}-G A C G T A A C C C G C A G A A G A A-3^{\prime}$ & 198 \\
\hline & 16SuniR: 5'-CGCCCAGTAATTCCGATTAA-3' & \\
\hline \multicolumn{3}{|l|}{ Housekeeping genes } \\
\hline \multirow[t]{2}{*}{$\beta$-actin } & Act2F: 5'-GCAGAGCAAACGTGGTAT-3' & 91 \\
\hline & Act2R: $5^{\prime}$-TGTGATGCCACACTTTCT-3' & \\
\hline \multirow[t]{2}{*}{ gapdh } & GapF: 5'-GGTGTCTTTACAACAATCG-3' & 148 \\
\hline & GapR: 5'-TAGATACGACCTTCATGTCAG-3' & \\
\hline
\end{tabular}

The following equation was used to calculate the numbers of amplicon copies into the purified template with a predetermined concentration: weight of PCR fragment $\left(\mathrm{g} \mathrm{\mu L}^{-1}\right) /\left(660 \mathrm{~g} \mathrm{~mol}^{-1} \times\right.$ pair bases number of the PCR fragment $) \times\left(6.023 \times 10^{23}\right)=$ number of genomic copies per microliter. ${ }^{99}$

Taking the number of amplicon copies of the purified templates per microliter, five 10-fold serial dilutions were made, ranging from $100 \mathrm{E}+07=10^{7}$ to $100 \mathrm{E}+03=10^{3}$ number of amplicon copies. These serial dilutions were used to generate the standard curves. All the standard curves had very similar efficiency and slope allowing the use of $2^{-(\Delta \Delta C t)}$ method for the relative quantification. ${ }^{100}$

In the esophageal bulb samples, the abundance of ' $\mathrm{Ca}$. Erwinia dacicola' 16S rDNA was calculated relative to the $B$. oleae $\beta$-actin reference, whereas in midgut samples, the abundance of ' $C a$. Erwinia dacicola' 16S rDNA and the abundance of the universal bacterial segment of $16 \mathrm{~S}$ rDNA were calculated relative to the $B$. oleae gapdh reference gene.

The $\Delta \mathrm{Ct}$ between the reference gene ( $B$. oleae $\beta$-actin and gapdh) and the target gene ('Ca. Erwinia dacicola' 16S rDNA and $16 \mathrm{~S}$ rDNA universal bacterial segment) was calculated for each sample as: $\Delta \mathrm{Ct}=\mathrm{Ct}_{\text {target gene }}-\mathrm{Ct}_{\text {reference gene. }}$ The $\Delta \Delta \mathrm{Ct}$ between the $\Delta \mathrm{Ct}$ of the treated samples and the average $\Delta \mathrm{Ct}$ of the control groups was then calculated using as: $\Delta \Delta \mathrm{Ct}=\Delta \mathrm{Ct}$ treatment - mean $\Delta \mathrm{Ct}$ control. Finally, the fold change $2^{-(\Delta \Delta \mathrm{Ct})}$ was calculated and averaged. Obtained data were log-transformed and the logarithm of the fold change $2^{-(\Delta \Delta C t)}$ was used as an index of the relative abundance of the bacterial loads in comparison with the control.

\subsection{Statistical analysis}

The analyzed parameters were: adult mortality rate, daily diet consumption, fecundity, number of offspring/female, relative bacterial load of 'Ca. Erwinia dacicola' and of total bacteria.

For both fitness and molecular data, distributions were analyzed, and the summary statistic calculated. Boxplots and bar charts of each distribution were generated.

One-way analysis of variance (ANOVA) was carried out for each parameter. Levene's test for homogeneity of variance from means and medians was performed to assess whether the assumption of homoscedasticity, required for ANOVA, was verified and $H_{0}$ was accepted with a $P$-value $\geq 0.05 \%$. The normality distribution of the residual was verified with the Shapiro-Wilk test with $W \geq 0.05$ and $P$ normal $\geq 0.05$. Tukey's pairwise post hoc test was used to identify the treatments that were statistically different and Dunnett's simultaneous test for level mean versus control mean revealed the treatments that statistically differ from the control. When data were not normally distributed, they were analyzed using the non-parametric Kruskal-Wallis test. Where significant differences were observed, post hoc comparisons were performed using Mann-Whitney post hoc tests.

Analysis of covariance (ANCOVA) was performed to investigate whether the variability in the analyzed parameters was linked with some variables. Sex and treatment concentration were used as covariates for bioassay data.

Statistical analyses of the results were carried out with Minitab 18 Statistical Software ${ }^{\circledR}$, GraphPad Prism $8^{\circledR}$, PAST $3{ }^{\oplus}$ and Microsoft Excel ${ }^{\circledR}$.

\section{RESULTS}

\subsection{Impact of experimental treatments on OLF fitness}

Taking into account all the recorded parameters, the overall outcome of the bioassays clearly indicates that both $\mathrm{CO}$ and Vi negatively affect OLF fitness.

The highest experimental concentration of $\mathrm{CO}(0.5 \%)$ led to a significant increase in adult mortality rate for both sexes (ANOVA, $F_{6,28}=7.621$; Dunnett's pairwise post hoc, $P=0.0224$, $P=0.0001$; for females and males respectively) (Fig. 1). Moreover, a dose-dependent mortality trend was observed for CO (ANCOVA, $F_{2,16}=16.00, P=0.00011$ ) (Fig. 1), which further corroborates the occurrence of direct toxicity of this compound on adult flies. None

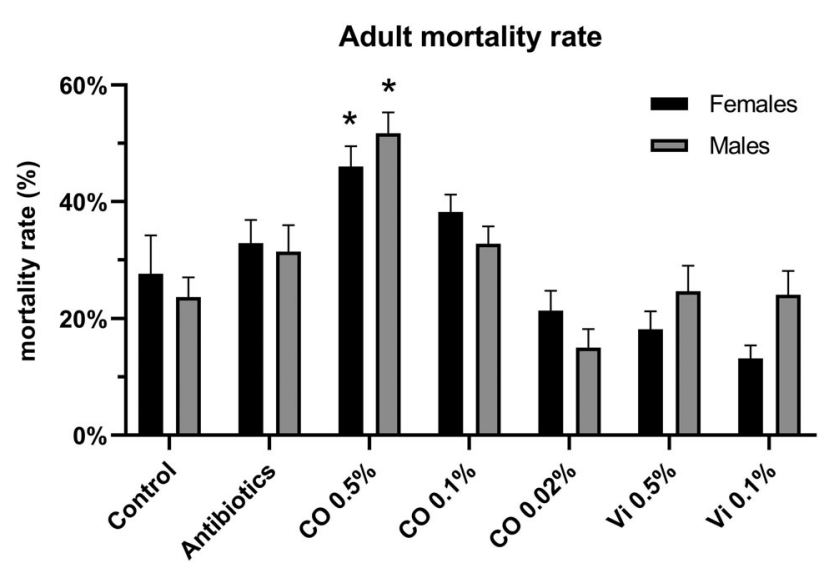

Figure 1. Mean $( \pm S E)$ adult mortality rate recorded on the 14 th day of treatment. Bars marked with an asterisk were significantly different from the mean registered for controls of the same sex (Dunnett's pairwise post-hoc test, $P<0.02$ ). Control flies were fed on a compound-free diet. Antibiotics cohorts were fed on a diet containing piperacillin. CO-treated flies were fed on a diet containing copper oxychloride at different concentrations $(0.5 \%, 0.1 \%, 0.02 \% \mathrm{w} / \mathrm{w})$. Vi-treated flies were fed on a diet containing viridiol at different concentrations $(0.5 \%, 0.1 \% \mathrm{w} / \mathrm{w})$. 
of the other experimental treatments had a significant impact on adult mortality (Fig. 1).

$\mathrm{CO}$ and $\mathrm{Vi}$ treatments had an overall negative impact on daily diet consumption, with an inverse correlation between treatment concentration and dietary intake (ANCOVA: treatment concentration: $\left.F_{1,10}>6.64, P<0.030\right)$. Reduced daily diet consumption, compared with controls, was observed for both sexes at higher $\mathrm{CO}$ doses (ANOVA, $F_{6,14}=12.67$; Dunnett's pairwise post-hoc $P=0.00015$ and $P=0.00028$ for females and males, respectively), and for females only for CO $0.1 \%$ and Vi $0.5 \%(P=0.0029$ and $P=0.0040$, respectively) (Fig. 2). Moreover, the dietary intake for each treatment was sexrelated, with a higher level of consumption in females (ANCOVA sex, $F_{1,10}>7.10, P<0.026$ ).

Overall fecundity (sum of the mean number of laid eggs/female recorded in the two oviposition tests) was significantly reduced only by the two higher CO concentrations (ANOVA, $F_{6,21}=10.44$; Dunnett's pairwise $P=0.00017$ and $P=0.00134$ for $0.5 \%$ and $0.1 \%$, respectively) (Fig. 3A).

The number of offspring per female was statistically lower for all compounds tested (ANOVA, $F_{6,21}=45.21$; Dunnett's pairwise $P<0.05)$ (Fig. 3B).

The results reported above indicate the occurrence of a direct negative impact of higher concentrations of the experimental compounds tested on OLF. However, their negative impact at lower concentrations on progeny development only, mirroring the antibiotic response, indicates that part of their overall effect on fitness is likely mediated by the negative impact they may have on OLF-associated microbiota, particularly the symbiont, which is essential for larval development.

\subsection{Alteration of associated bacterial community}

The qPCR results showed a widespread negative impact exerted by several experimental treatments on the load of the main bacterial endosymbiont of $B$. oleae, ' $C a$. Erwinia dacicola', in both the esophageal bulb (Fig. 4A) and the midgut (Fig. 4B). Endosymbiotic bacterial load in esophageal bulb samples was significantly lower (Kruskal-Wallis, $P<0.036$ ) in all experimental treatments, compared with controls, except for the lowest $\mathrm{CO}$ concentration (0.02\%) (Fig. 4B). The endosymbiotic bacterial titer in the midgut

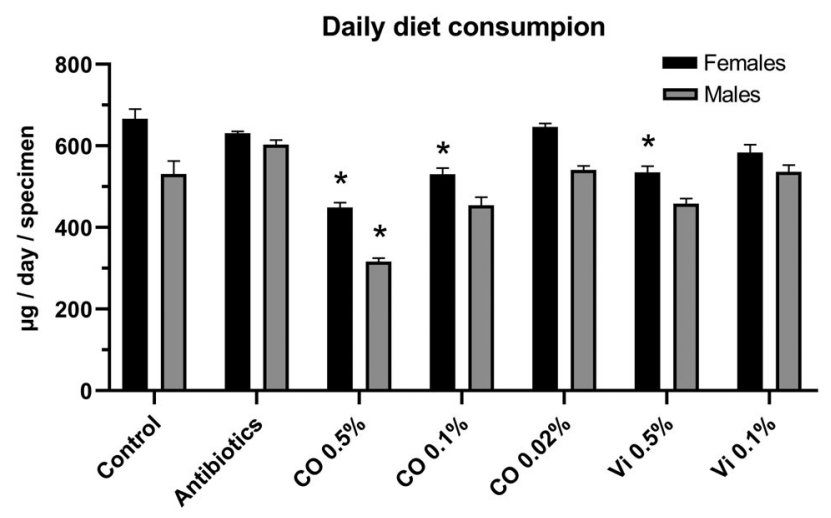

Figure 2. Mean $( \pm S E)$ daily diet consumption. Bars marked with an asterisk were significantly different from the mean registered for controls of the same sex (Dunnett's pairwise post-hoc test, $P<0.004$ ). Control flies were fed on a compound-free diet. Antibiotics cohorts were fed on a diet containing piperacillin. CO-treated flies were fed on a diet containing copper oxychloride at different concentrations $(0.5 \%, 0.1 \%, 0.02 \% \mathrm{w} / \mathrm{w})$. Vi-treated flies were fed on a diet containing vridiol at different concentrations $(0.5 \%, 0.1 \% \mathrm{w} / \mathrm{w})$.

\section{(A) \\ Females' fecundity}



(B)

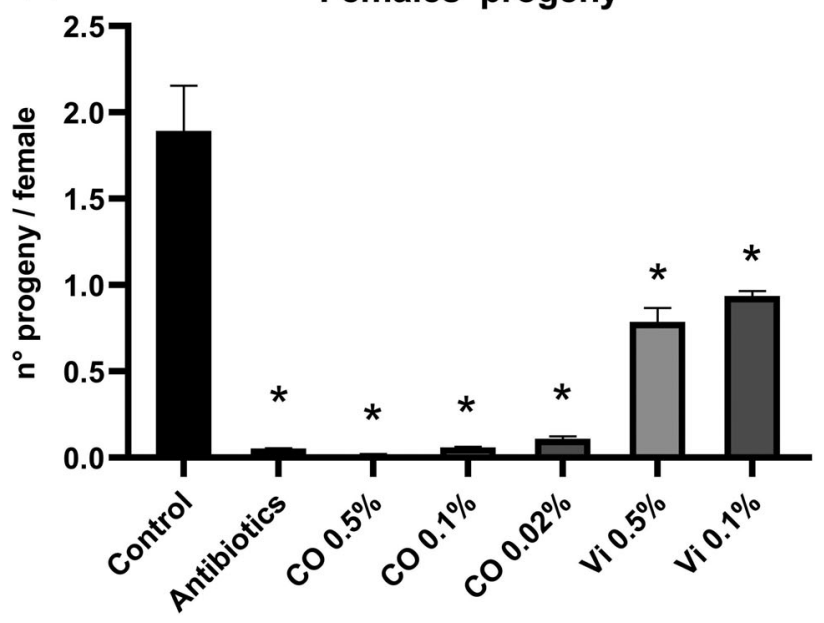

Figure 3. Mean $( \pm S E)$ females fecundity $(A)$ and mean number of offspring/female (B). Bars marked with an asterisk were significantly different from the control mean (Dunnett's pairwise post-hoc test, $P<0.03$ ). Control flies were fed on a compound-free diet. Antibiotics cohorts were fed on a diet containing piperacillin. CO-treated flies were fed on a diet containing copper oxychloride at different concentrations $(0.5 \%, 0.1 \%$, $0.02 \% \mathrm{w} / \mathrm{w})$. Vi-treated flies were fed on a diet containing viridiol at different concentrations $(0.5 \%, 0.1 \% \mathrm{w} / \mathrm{w})$.

was significantly lower in all treated insects, except for the lowest concentration of $\mathrm{CO}$ and $\mathrm{Vi}(0.02 \%$ and $0.1 \%$, respectively) (Kruskal-Wallis, $P<0.036$ ) (Fig. 4B). These results are in tune with the reduced fitness recorded in the bioassay, which is associated with a widespread decrease in the endosymbiont titer.

The total bacterial community resident in the midgut was significantly lower in all experimental treatments (Kruskal-Wallis, $P<0.0121)$, except for the antibiotic and the lowest concentration of $\mathrm{CO}(0.02 \%)$ (Fig. 5). These results suggest that $\mathrm{CO}$ and $\mathrm{Vi}$ have a broad and more intense effect on the gut microbial community, whereas the high specificity of piperacillin on Enterobacteriaceae may likely allow development of resistant bacteria harbored in the gut.

\section{DISCUSSION AND CONCLUSION}

To impair the fitness of insect pests, several authors suggested the use of symbioticide compounds to interrupt vertical transmission 
(A)

\section{Endosymbiotic bacteria load in oesophageal bulb}

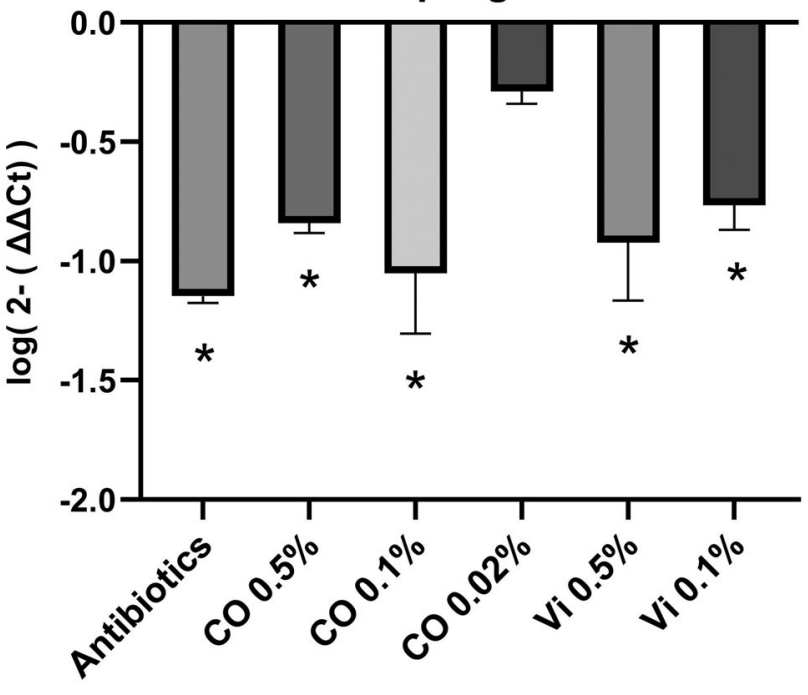

(B)

\section{Endosymbiotic bacteria load in midgut}

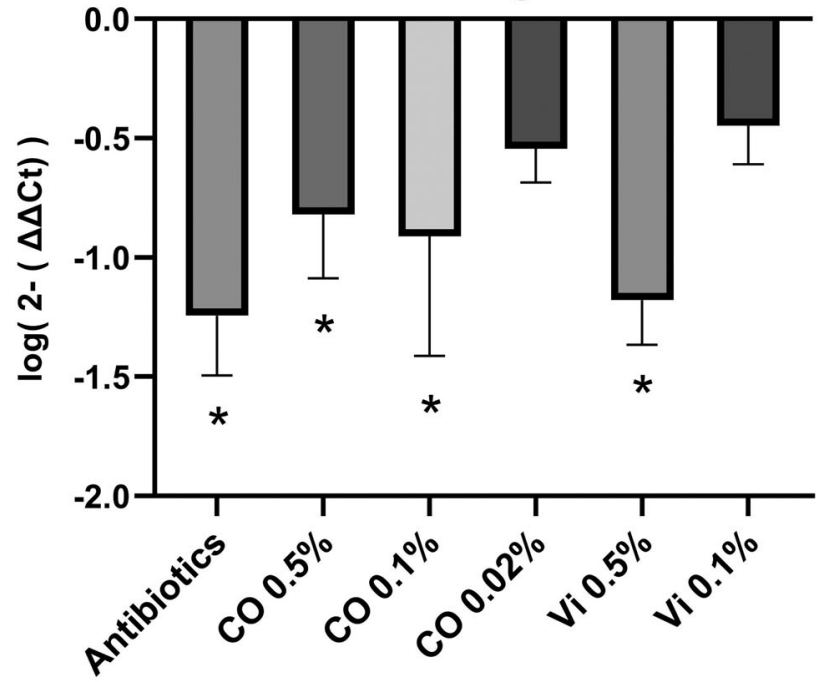

Figure 4. Mean $( \pm$ SE) endosymbiotic bacterial load resulted from qPCR and expressed as log $\left(2^{-(\Delta \Delta \mathrm{Ct})}\right)$ in oesophageal bulb $(\mathrm{A})$ and midgut (B) samples of Bactrocera oleae females. The zero-level corresponds to the mean control load. Bars marked with an asterisk were significantly different from the control mean in the Mann-Whitney's pairwise post-hoc test. Control flies were fed on a compound-free diet. Antibiotics cohorts were fed on a diet containing piperacillin. CO-treated flies were fed on a diet containing copper oxychloride at different concentrations $(0.5 \%$, $0.1 \%, 0.02 \% \mathrm{w} / \mathrm{w})$. Vi-treated flies were fed on a diet containing viridiol at different concentrations $(0.5 \%, 0.1 \% \mathrm{w} / \mathrm{w})$.

of primary insect endosymbionts. ${ }^{31-33}$ Here, we test the potential of symbiosis disruption for control of Bactrocera oleae, one of the major agricultural pests of olive orchards.

Bioassays performed in this study, across two subsequent generations, allowed us to tease apart: (i) the direct negative impact (i.e. mortality, reduced food intake, reduced fecundity) of the experimental compounds; and (ii) indirect effects mediated by alteration in the symbiotic load and gut-associated microbial community (i.e. larval progeny development, number of
Microbiota load alteration in midgut

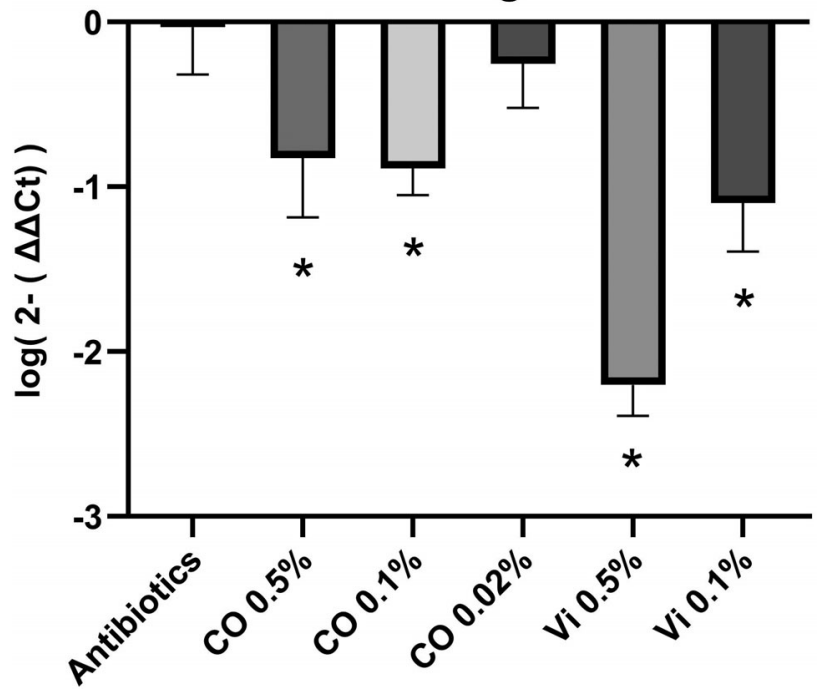

Figure 5. Mean $( \pm \mathrm{SE})$ total bacterial load resulted by qPCR and expressed as log $\left(2^{-(\Delta \Delta C t)}\right)$ in midgut samples of Bactrocera oleae females. The zerolevel corresponds to the mean control load. Bars marked with an asterisk were significantly different from the control mean in the Mann-Whitney's pairwise post-hoc test. Control flies were fed on a compound-free diet. Antibiotics cohorts were fed on a diet containing piperacillin. CO-treated flies were fed on a diet containing copper oxychloride at different concentrations $(0.5 \%, 0.1 \%, 0.02 \% \mathrm{w} / \mathrm{w})$. Vi-treated flies were fed on a diet containing viridiol at different concentrations $(0.5 \%, 0.1 \% \mathrm{w} / \mathrm{w})$.

offspring). Reduced survival and fecundity of treated flies are due to a direct negative impact of the administered compound. In fact, it is known that the presence of ' $\mathrm{Ca}$. Erwinia dacicola' is irrelevant for $B$. oleae females' fecundity when flies are reared on a nitrogen-free diet, as in our experimental bioassays. ${ }^{59,60}$ This was also confirmed by our results because the survival and fecundity of aposymbiotic females, treated with antibiotics, were not statistically different from controls. On the contrary, the survival and fecundity of CO-treated flies were highly reduced in a dosedependent manner, as expected based on previous studies demonstrating copper toxicity on insects. ${ }^{92-95}$ By contrast, $\mathrm{Vi}$ treatment did not affect female survival and fecundity, displaying no significant toxic effect.

The presence of ' $\mathrm{C}$. Erwinia dacicola' is essential for $\mathrm{B}$. oleae larval survival in unripe olive fruit. ${ }^{53}$ Our results demonstrate that the reduction in fitness induced by some of the experimental treatments may be exclusively due to their negative impact on insect-associated microorganisms. Indeed, the number of offspring per female clearly decreases in treated insects, suggesting an anti-symbiotic effect of the administered compounds. Antibiotic treatment led to a drastic reduction in the number of offspring of up to $97 \%$, compared with the control cohort, in agreement with previous results by Ben-Yosef et $a l^{53}$ In addition, all the administered compounds led to a signifcant reduction in offspring, with a decrease ranging from $99 \%$ to $\sim 50 \%$, for CO $0.5 \%$ and Vi $0.1 \%$, respectively. It is worth noting in the case of $\mathrm{Vi}$, these results are associated with a total absence of direct negative effects on OLF. This is an interesting issue when considering the direct toxic effect this compound may have on nontarget arthropods.

In the case of $\mathrm{CO}$, the higher experimental concentrations used $(0.5 \%$ and $0.1 \%)$ had a direct toxic effect, which reduced the 
number of eggs laid by females, further reinforcing the negative impact on insect fitness mediated by a reduction in symbionts. Our study provides additional evidence for an anti-symbiotic effect of CO on OLF and a possible explanation for the high larval mortality reported in CO-sprayed olive fruits. ${ }^{83-90}$ In the current study, there is strong evidence that the oral administration of CO can affect both OLF adult and larval fitness, as a result of both a toxic and a symbioticide effect. The symbioticide effect persists at the lowest concentration used, whereas a strong toxic effect occurs when higher doses are used supporting the toxicity of copper for insects in a dose-dependent manner. ${ }^{84-87}$ The double effect of CO could make this compound particularly useful for OLF control, as suggested by previous field observations. ${ }^{92-95} \mathrm{~A}$ recent study by Bigiotti et al. demonstrated the symbioticide effect on OLF of two different copper products after oral administration. $^{74}$

The quantification of microbial loads in OLF exposed to the experimental treatments clearly indicates that the capacity of larvae to develop in unripe olives is highly dependent on the presence of primary symbionts, which are affected to a differing extent by the compounds tested. Changes in progeny development can be linked to substantial changes in ' $\mathrm{Ca}$. Erwinia dacicola' load but treatments also strongly affected the entire microbiome composition. If and how alterations of the whole bacterial community compared with 'Ca. Erwinia dacicola' are partially responsible for the observed fitness reduction remains to be studied.

Our results shed light on the possible use of natural products for symbiotic control of OLF. Indeed, Vi has a strong negative impact on endosymbiont load and on the overall load of gut microbiota, which is associated with a reduced OLF larval survival. Vi has shown remarkable antibiotic activities against some bacteria and phytopathogenic fungi, ${ }^{76-82}$ but, to our knowledge, this is the first time that a fungal metabolite has been used for symbiotic control of OLF, via the disruption of its endosymbiotic bacterial load. Interestingly, the fungal metabolite 3-O-methylfunicone from a beneficial endophytic strain of Talaromyces pinophilus displayed toxic effects against the pea aphid Acyrthosiphon pisum (Homoptera, Aphidiidae). ${ }^{76}$

In conclusion, our results pave the way for use of this natural compound to disrupt $B$. oleae endosymbiosis, fostering the development of more sustainable strategies of OLF control. However, even though the absence of direct negative effects on OLF adults exerted by the lower concentration of $\mathrm{CO}$ and $\mathrm{Vi}$ appears promising in terms of possible toxic effects on non-target arthropods, further studies are needed to assess the risk associated with use of these compounds.

\section{AUTHOR CONTRIBUTIONS}

FP, APG, SL, DG, FV, and MS conceived and designed the study. MS conducted experiments. $A B$ assisted in the qPCR set-up. FV provided the fungal metabolites. FP and MS wrote the manuscript, and $A P G, S L, A B, F V$, and DG revised and improved the manuscript. All authors reviewed and approved the final version of the manuscript.

\section{ACKNOWLEDGEMENTS}

This work was supported by the following projects: MIURPON (grant number Linfa 03PE_00026_1; grant number Marea 03PE_00106); POR FESR CAMPANIA 2014/2020- O.S. 1.1 (grant number Bioagro 559); MISE CRESO (grant number Protection n. F/050421/01-03/X32); PSR Veneto 16.1.1 (grant number Divine n. 3589659); COST Action FA1405 (grant number: COST-STSMECOST-STSM-FA1405-270217-083727); and the Région Centre Project Insect Effect to DG (grant number: 2014-00094521). Thanks are due to Paola Varricchio, Rosalba Ferrara and Ilaria Di Lelio (Department of Agricultural Sciences, University of Naples, Federico II) for their help in the set-up of molecular experiments, to Francesco Nugnes (CNR Institute for Sustainable Plant Protection, 80055 Portici (NA), Italy) for his help with the DGGE analysis, and to Prof. Antonio Belcari and Prof. Patrizia Sacchetti (Department of Agrifood Production and Environmental Sciences - DISPAA, University of Florence, Florence, Italy) for sharing their know-how about the $B$. oleae rearing and bioassay set up.

\section{SUPPORTING INFORMATION}

Supporting information may be found in the online version of this article.

\section{REFERENCES}

1 Pereira JA, Alves MR, Casal S and Oliveira MB, Effect of olive fruit fly infestation on the quality of olive oil from cultivars Cobrancosa, Madural and Verdeal Transmontana. Ital J Food Sci 16:355-365 (2004).

2 Malheiro R, Casal S, Baptista P and Pereira JA, Physico-chemical characteristics of olive leaves and fruits and their relation with Bactrocera oleae (Rossi) cultivar oviposition preference. Sci Hort 194:208-214 (2015).

3 Medjkouh L, Tamendjari A, Keciri S, Santos J, Nunes MA and Oliveira MB, The effect of the olive fruit fly (Bactrocera oleae) on quality parameters, and antioxidant and antibacterial activities of olive oil. Food Funct 7:2780-2788 (2016).

4 Montiel Bueno $A$ and Jones $O$, Alternative methods for controlling the olive fly, Bactrocera oleae, involving semiochemicals. IOBC/WPRS Bull 25:1-11 (2002).

5 Thomas DB and Mangan RL, Nontarget impact of spinosad GF-120 bait sprays for control of the Mexican fruit fly (Diptera: Tephritidae) in Texas citrus. J Econ Entomol 98:1950-1956 (2005).

6 Skouras PJ, Margaritopoulos JT, Seraphides NA, loannides IM and Kakani EG, Organophosphate resistance in olive fruit fly, Bactrocera oleae, populations in Greece and Cyprus. Pest Manag Sci 63:42-48 (2007).

7 Kakani EG and Mathiopoulos KD, Organophosphate resistancerelated mutations in the acetyl-cholinesterase gene of Tephritidae. J Appl Entomol 132:762-771 (2008).

8 Margaritopoulos JT, Skavdis G, Kalogiannis N, Nikou D and Morou E, Efficacy of the pyrethroid alpha-cypermethrin against Bactrocera oleae populations from Greece, and improved diagnostic for an iAChE mutation. Pest Manag Sci 64:900-908 (2008).

9 Stasinakis P, Katsares V and Mavragani-Tsipidou P, Organophosphate resistance and allelic frequencies of esterases in the olive fruit fly Bactrocera oleae (Diptera: Tephritidae). J Agric Urban Entomol 18: 157-168 (2001).

10 Kakani EG, Zygouridis NE, Tsoumani KT, Seraphides N, Zalom FG and Mathiopoulos KD, Spinosad resistance development in wild olive fruit fly Bactrocera oleae (Diptera: Tephritidae) populations in California. Pest Manag Sci 66:447-453 (2010).

11 Kampouraki A, Stavrakaki M, Karataraki A, Katsikogiannis G, Pitika E, Varikou K et al., Recent evolution and operational impact of insecticide resistance in olive fruit fly Bactrocera oleae populations from Greece. J Pest Sci 91:1429-1439 (2018).

12 Vontas J, Hernandez-Crespo P, Margaritopoulos JT, Ortego F, Feng HT, Mathiopoulos KD et al., Insecticide resistance in Tephritid flies. Pest Biochem Physiol 100:199-205 (2011).

13 Pavlidi N, Kampouraki A, Tseliou V, Wybouw N, Dermauw W, Roditakis E et al., Molecular characterization of pyrethroid resistance in the olive fruit fly Bactrocera oleae. Pestic Biochem Phys 148:1-7 (2018).

14 Spanedda AF and Terrosi A, A field method for assessing the harmfulness to olive tree entomofauna of pesticides used for olive fly 
control. In: Vitagliano C, Martelli GP (eds) Proceedings of the 4th International Symposium on olive growing, Valenzano, Italy, 25-30 September 2000. Acta Hortic 586:849-852 (2002).

15 Spanedda AF and Terrosi A, Toxic residue patterns in olive fruit, oil, and waste water of the most common insecticides used for controlling olive fly in Central Italy. In: Proceedings of the 4th International Symposium on olive growing, Valenzano, Italy, 25-30 September 2000. Acta Hortic 586:853-856 (2002).

16 Daane KM and Johnson MW, Olive fruit fly: managing an ancient pest in modern times. Annu Rev Entomol 55:151-169 (2010).

17 Hladnik M, A review of plant protection against the olive fly (Bactrocera oleae (Rossi, 1790) Gmelin) and molecular methods to monitor the insecticide resistance alleles. Acta Agr Slov 109:135 (2017).

18 Dias NP, Zotti MJ, Montoya P, Carvalho IR and Nava DE, Fruit fly management research: a systematic review of monitoring and control tactics in the world. Crop Prot 112:187-200 (2018).

19 Raspi A and Loni A, Alcune note sull'allevamento di Opius concolor (Szèpl.) (Hymenoptera: Braconidae) e su recenti tentativi d'introduzione della specie in Toscana ed in Liguria. Frustula Entomol 17: 135-145 (1994).

20 Wharton RA, Classical biological control of fruit-infesting Tephritidae, in World Crop Pests: Fruit Flies-Their Biology, Natural Enemies and Control, 3B, ed. by Robinson AS and Hooper G. Elsevier, Amsterdam, pp. 303-313 (1989).

21 Miranda MA, Miquel M, Terrassa J, Melis N and Monerris M, Parasitism of Bactrocera oleae (Diptera, Tephritidae) by Psyttalia concolor (Hymenoptera, Braconidae) in the Balearic Islands (Spain). J Appl Entomol 132:798-805 (2008).

22 Yokoyama VY, Rendon PA and Sivinsk J, Psyttalia cf. concolor (Hymenoptera: Braconidae) for biological control of olive fruit fly (Diptera: Tephritidae) in California. Environ Entomol 37:764-773 (2008).

23 Noce ME, Belfiore T, Scalercio S, Vizzarri V and lannotta N, Efficacy of new mass-trapping devices against Bactrocera oleae (Diptera Tephritidae) for minimizing pesticide input in agroecosystems. J Environ $\mathrm{SCi}$ Health B 44:442-448 (2009).

24 Estes AM, Nestel D, Belcari A, Jessup A, Rempoulakis $P$ and Economopoulos AP, A basis for the renewal of sterile insect technique for the olive fly, Bactrocera oleae (Rossi). J Appl Entomol 136: 1-16 (2011).

25 Canale A and Benelli G, Impact of mass-rearing on the host seeking behavior and parasitism by the fruit fly parasitoid Psyttalia concolor (Szépligeti) (Hymenoptera: Braconidae). J Pest Sci 85:65-74 (2012).

26 Sagri E, Reczko M, Tsoumani KT, Gregoriou ME, Harokopos V, Mavridou AM et al., The molecular biology of the olive fly comes of age. BMC Genet 15:S8 (2014).

27 Fabbri A, Lambardi M and Ozden-Tokatli Y, Olive breeding, in Breeding Plantation Tree Crops: Tropical Species, ed. by Jain SM and Priyadarshan PM. Springer, New York, NY, pp. 423-465 (2009).

28 Corrado G, Alagna F, Rocco M, Renzone G, Varricchio P, Coppola V et al., Molecular interactions between the olive and the fruit fly Bactrocera oleae. BMC Plant Biol 12:86 (2012).

29 Alagna F, Kallenbach M, Pompa A, De Marchis F, Rao R, Baldwin IT et al., Olive fruits infested with olive fly larvae respond with an ethylene burst and the emission of specific volatiles. J Integr Plant Biol 58:413-425 (2016).

30 Grasso F, Coppola M, Carbone F, Baldoni L, Alagna F, Perrotta G et al., The transcriptional response to the olive fruit fly (Bactrocera oleae) reveals extended differences between tolerant and susceptible olive (Olea europaea L.) varieties. PLoS ONE 12:e0183050 (2017).

31 Darby AC, Symbiosis research as a novel strategy for insect pest control, in Biorational Control of Arthropod Pests: Application and Resistance Management, ed. by Ishaaya I and Horowitz AR. Springer, Dordrecht, The Netherlands, pp. 207-231 (2009).

32 Klepzig KD, Adams AS, Handelsman J and Raffa KF, Symbioses: a key driver of insect physiological processes, ecological interactions, evolutionary diversification, and impacts on humans. Environ Entomol 38:67-77 (2009).

33 Arora AK and Douglas AE, Hype or opportunity? Using microbial symbionts in novel strategies for insect pest control. J Insect Physiol 103: 10-17 (2017).

34 Giron D, Dedeine F, Dubreuil G, Huguet E and Mouton L, Influence of microbial symbionts on plant-insect interactions, in Insect-Plant Interactions in a Crop Protection Perspective, Vol. 81, ed. by
Sauvion N, Thiéry D and Calatayud P. Elsevier, GBR, Oxford, pp. 225-257 (2017).

35 Douglas AE, Microbial brokers of insect-plant interactions revisited. $J$ Chem Ecol 39:952-961 (2013).

36 Macke E, Tasiemski A, Massol F, Callens M and Decaestecker E, Life history and eco-evolutionary dynamics in light of the gut microbiota. Oikos 126:508-531 (2017).

37 Relman DA, 'Til death do us part': coming to terms with symbiotic relationships. Nat Rev 6:721-724 (2008).

38 Vasanthakumar A, Handelsman IJ, Schloss P, Bauer L and Raffa KF, Gut microbiota of an invasive wood boring beetle, the emerald ash borer: community composition and structure across different life stages. Environ Entomol 37:1344-1353 (2008).

39 Giron D, Dubreuil G, Bennett A, Dedeine F, Dicke M, Dyer LA et al., Promises and challenges in insect-plant interactions. Entomol Exp Appl 166:319-343 (2018).

40 Login FH, Balmand S, Vallier A, Vincent-Monegat C, Vigneron A, WeissGayet $M$ et al., Antimicrobial peptides keep insect endosymbionts under control. Science 334:362-365 (2011).

41 Le-Feuvre RR, Ramírez CC, Olea N and Meza-Basso L, Effect of the antimicrobial peptide indolicidin on the green peach aphid Myzus persicae (Sulzer). J Appl Entomol 131:71-75 (2007).

42 Luna-Ramirez K, Skaljac M, Grotmann J, Kirfel P and Vilcinskas A, Orally delivered scorpion antimicrobial peptides exhibit activity against pea aphid (Acyrthosiphon pisum) and its bacterial symbionts. Toxins 9:261 (2017).

43 Petri L, Ricerche sopra i batteri intestinali della mosca olearia. Roma, Memorie della Regia Stazione di Patologia Vegetale di Roma (1909).

44 Capuzzo C, Firrao G, Mazzon L, Squartini A and Girolami V, 'Candidatus Erwinia dacicola', a co-evolved symbiotic bacterium of the olive fly Bactrocera oleae (Gmelin). Int J Syst Evol Microbiol 55:1641-1647 (2005).

45 Belcari A, Sacchetti P, Marchi G and Surico G, La mosca delle olive e la simbiosi batterica. Inf Fitopatol 9:55-59 (2003).

46 Sacchetti P, Granchietti A, Landini S, Viti C, Giovannetti L and Belcari A, Relationships between the olive fly and bacteria.J Appl Entomol 132: 682-689 (2008).

47 Estes AM, Life in a fly: the ecology and evolution of the olive fly endosymbiont, Candidatus Erwinia dacicola. PhD thesis, University of Arizona (2009).

48 Estes AM, Hearn DJ, Burrack HJ, Rempoulakis P and Pierson EA, Prevalence of Candidatus Erwinia dacicola in wild and laboratory olive fruit fly populations and across developmental stages. Environ Entomol 41:265-274 (2012).

49 Kounatidis I, Crotti E, Sapountzis P, Sacchi L, Rizzi A, Chouaia B et al., Acetobacter tropicalis is a major symbiont of the olive fruit fly (Bactrocera oleae). Appl Environ Microbiol 75:3281-3288 (2009).

50 Savio C, Mazzon L, Martinez-Sanudo I, Simonato M, Squartini A and Girolami V, Evidence of two lineages of the symbiont "Candidatus Erwinia dacicola" in Italian populations of Bactrocera oleae (Rossi) based on 16S rRNA gene sequences. Int J Syst Evol Micrbiol 62: 179-187 (2012).

51 Paracer S and Ahmadjian V, Symbiosis: An Introduction to Biological Associations, 2nd edn. Oxford University Press, Oxford (2000).

52 Ishikawa H, Insect symbiosis: an introduction, in In Insect Symbiosis, ed. by Bourtzis $\mathrm{K}$ and Miller T. CRC Press, Boca Raton, FL, pp. 1-16 (2003).

53 Ben-Yosef M, Pasternak Z, Jurkevitch E and Yuval B, Symbiotic bacteria enable olive fly larvae to overcome host defences. Roy Soc Open Sci 2:150-170 (2015).

54 Ras E, Beukeboom LW, Càceres C and Bourtzis K, Review of the role of gut microbiota in mass rearing of the olive fruit fly, Bactrocera oleae, and its parasitoids. Entomol Exp Appl 164:237-256 (2017).

55 Dimou I, Rempoulakis P and Economopoulos AP, Olive fruit fly [Bactrocera (Dacus) oleae (Rossi) (Diptera: Tephritidae)] adult rearing diet without antibiotic. J Appl Entomol 134:72-79 (2010).

56 Sacchetti P, Ghiardi B, Granchietti A, Stefanini FM and Belcari A, Development of probiotic diets for the olive fly: evaluation of their effects on fly longevity and fecundity. Ann Appl Biol 164:138-150 (2014).

57 Sacchetti P, Pastorelli R, Bigiotti G, Guidi R, Ruschioni S, Viti C et al., Olive fruit fly rearing procedures affect the vertical transmission of the bacterial symbiont Candidatus Erwinia dacicola. BMC Biotechnol 19:91 (2019).

58 Bigiotti G, Pastorelli R, Guidi R, Belcari A and Sacchetti P, Horizontal transfer and finalization of a reliable detection method for the olive 
fruit fly endosymbiont, Candidatus Erwinia dacicola. BMC Biotechnol 19:1-12 (2019).

59 Ben-Yosef $M$, Aharon $Y$, Jurkevitch E and Yuval B, Give us the tools and we will do the job: symbiotic bacteria affect olive fly fitness in a dietdependent fashion. $P$ Roy Soc B 277:1545-1552 (2010).

60 Ben-Yosef M, Pasternak Z, Jurkevitch E and Yuval B, Symbiotic bacteria enable olive flies (Bactrocera oleae) to exploit intractable sources of nitrogen. J Evol Biol 27:2695-2705 (2014).

61 Blow F, Gioti A, Goodhead IB, Kalyva M, Kampouraki A, Vontas J et al., Functional genomics of a symbiotic community: shared traits in the olive fruit fly gut microbiota. Genome Biol Evol 12:3778-3791 (2020).

62 Polpass AJ, Ben-Yosef M, Jurkevitch E and Yuval B, Symbiotic bacteria affect oviposition behavior in the olive fruit fly Bactrocera oleae. $J$ Insect Physiol 117:103917 (2019).

63 Fletcher BS, The biology of dacine fruit flies. Annu Rev Entomol 32: 115-144 (1987).

64 Greany PD, Host plant resistance to tephritids: an under-exploited control strategy, in Fruit Flies: Their Biology, Natural Enemies and Control, ed. by Robinson AS and Hooper G. Elsevier Science, Amsterdam, pp. 353-362 (1989).

65 Messina FJ and Jones VP, Relationship between fruit phenology and infestation by the apple maggot (Diptera: Tephritidae) in Utah. Ann Entomol Soc Am 83:742-752 (1990).

66 Joachim-Bravo IS, Fernandes OA, Bortoli SRA and Zucoloto FS, Oviposition behavior of Ceratitis capitata Wiedemann (Diptera: Tephritidae): association between oviposition preference and larval performance in individual females. Neotrop Entomol 30:559-564 (2001).

67 Rattanapun W, Amornsak W and Clarke AR, Bactrocera dorsalis preference for and performance on two mango varieties at three stages of ripeness. Entomol Exp Appl 131:243-253 (2009).

68 Kapatos ET and Fletcher BS, The phenology of the olive fly, Dacus oleae (Gmel.) (Diptera, Tephritidae), in Corfu. Z Angew Entomol 97: 360-370 (1984).

69 Neuenschwander P, Michelakis S, Holloway P and Berchtol W, Factors affecting the susceptibility of fruits of different olive varieties to attack by Dacus oleae (Gmel.) (Dipt., Tephritidae). Z Angew Entomol 100:174-188 (1985).

70 Whitehead SR and Bowers MD, Evidence for the adaptive significance of secondary compounds in vertebrate-dispersed fruits. Am Nat 182: 563-577 (2013).

71 Gutierrez-Rosales F, Romero MP, Casanovas M, Motilva MJ and Minguez-Mosquera Ml, $\beta$-Glucosidase involvement in the formation and transformation of oleuropein during the growth and development of olive fruits (Olea europaea L. cv. Arbequina) grown under different farming practices. J Agric Food Chem 60:4348-4358 (2012).

72 Amiot MJ, Fleuriet A and Macheix JJ, Importance and evolution of phenolic compounds in olive during growth and maturation. $J$ Agric Food Chem 34:823-826 (1986).

73 Pavlidi N, Gioti A, Wybouw N, Dermauw W, Ben-Yosef M, Yuval B et al., Transcriptomic responses of the olive fruit fly Bactrocera oleae and its symbiont Candidatus Erwinia dacicola to olive feeding. Nature Sci Rep 7:42633 (2017).

74 Bigiotti G, Pastorelli R, Belcari A and Sacchetti P, Symbiosis interruption in the olive fly: effect of copper and propolis on Candidatus Erwinia dacicola. J Appl Entomol 143:357-364 (2019).

75 Rubio MB, Hermosa R, Reino JL, Collado IG and Monte E, Thctf1 transcription factor of Trichoderma harzianum is involved in 6-pentyl-2Hpyran-2-one production and antifungal activity. Fungal Genet Biol 46:17-27 (2009).

76 Vinale F, Sivasithamparam K, Ghisalberti EL, Marra R, Barbetti MJ, Li H et al., A novel role for Trichoderma secondary metabolites in the interactions with plants. Physiol Mol Plant Pathol 72:1-3 (2008).

77 Vinale F, Sivasithamparam K, Ghisalberti EL, Ruocco M, Woo SL and Lorito M, Trichoderma secondary metabolites that affect plant metabolism. Nat Prod Commun 7:1545-1550 (2012).

78 Keswani C, Singh HB, Hermosa R, García-Estrada C, Caradus J, He Y et al., Antimicrobial secondary metabolites from agriculturally important fungi as next biocontrol agent. Appl Microbiol Biotechnol 103:9287-9303 (2019).

79 Moffatt JS, Bu'Lock JD and Yuen TH, Viridiol, a steroid-like product from Trichoderma viride. J Chem Soc Chem Commun 14:839 (1969).
80 Howell CR and Stipanovic RD, Effect of sterol biosynthesis inhibitors on phytotoxin (viridiol) production by Gliocladium virens in culture. Phytopathology 84:969-972 (1994).

81 de Souza Sebastianes FL, Montes Peral Valente AM, Boffo EF, Ferreira AG, Soares Melo I, Beraldo Moraes LA et al., Isolation of the antibacterial agent Viridiol from the Mangrove endophytic fungus Hypocrea virens, as monitored by a biologic assay against Escherichia coli and NMR spectroscopy. Current Biotec 6:325 (2017).

82 Vinale F, Nicoletti R, Lacatena F, Marra R, Sacco A, Lombardi $\mathrm{N}$ et al., Secondary metabolites from the endophytic fungus Talaromyces pinophilus. Nat Prod Res 31:1778-1785 (2017).

83 Tzanakakis ME, Considerations on the possible usefulness of olive fruit fly symbionticides in integrated control in olive groves, in Integrated Pest Control in Olive-Groves, ed. by Cavalloro R and Crovetti A, Proc CEC/FAO/IOBC, International Joint Meeting, Pisa, Italy, 3-6 April 1984. Rotterdam, A.A. Balkema, pp. 386-393 (1985).

84 Belcari $A$ and Bobbio E, L'impiego del rame nel controllo della mosca delle olive, Bactrocera oleae. Inf Fitopatol 12:52-55 (1999).

85 Sacchetti P, Belcari A and Del Pianta R, Utilizzo di prodotti ad azione antibatterica per il controllo della mosca delle olive, in La difesa dai fitofagi in condizioni di olivicoltura biologica, Atti Accademia nazionale dell'Olivo e dell'Olio, Spoleto, 29-30 October 2002. Spoleto, Accademia Nazionale dell'Olio e dell'Olivo, pp. 23-33 (2004).

86 Belcari A, Sacchetti P, Rosi MC and Del Pianta R, Control of the olive fly (Bactrocera oleae) through the use of copper products in Central Italy. IOBC/WPRS Bull 28:45-48 (2005).

87 Tsolakis H, Ragusa E and Tarantino P, Control of Bactrocera oleae by low environmental impact methods: NPC methodology to evaluate the efficacy of lure-and-kill method and copper hydroxide treatments. Bull Insectology 64:1-8 (2011).

88 Caleca V, Lo Verde G, Lo Verde V, Piccionello MP and Rizzo R, Control of Bactrocera oleae and Ceratitis capitata in organic orchards: use of clays and copper products. Acta Hortic 873:227-234 (2010).

89 Gonçalves $\mathrm{F}$ and Torres $\mathrm{L}$, Effect of copper oxychloride on the olive infestation by Bactrocera oleae in northeastern Portugal. Acta Hortic 949:333-340 (2012).

90 Rosi MC, Sacchetti P, Librandi M and Belcari A, Effectiveness of different copper products against the olive fly in organic olive groves. IOBC/WPRS Bull 30:277-281 (2007).

91 Prophetou-Athanasiadou DA, Tzanakakis ME, Myroyannis D and Sakas G, Deterrence of oviposition in Dacus oleae by copper hydroxide. Entomol Exp Appl 61:1-5 (1991).

92 Jensen $\mathrm{P}$ and Trumble JT, Ecological consequences of bioavailability of metals and metalloids. Recent Res Dev Entomol 4:1-17 (2003).

93 Cheruiyot DJ, Investigation of elemental defense and trophic transfer of metals using beet armyworm, Spodoptera exigua, Hübner. PhD dissertation. Auburn University (2012).

94 Majumdar TN and Gupta A, Acute and chronic toxicity of copper on aquatic insect Chironomus ramosus from Assam, India. J Environ Biol 33:139-142 (2012).

95 Cheruiyot DJ, Boyd RS, Coudron TA and Cobine PA, Biotransfer, bioaccumulation, and effects of herbivore dietary $\mathrm{Co}, \mathrm{Cu}, \mathrm{Ni}$, and $\mathrm{Zn}$ on growth and development of the insect predator. Podisus maculiventris (say). J Chem Ecol 39:764-772 (2013).

96 Zervas GA, Reproductive physiology of Dacus oleae (Gmel.) (Diptera: Trypetidae). Comparison of a wild and artificially reared flies. Geoponika 282:10-14 (1982).

97 Nadkarni M, Martin FE, Jacques NA and Hunter N, Determination of bacterial load by real-time PCR using a broad range (universal) probe and primer set. Microbiology 148:257-266 (2002).

98 Sagri E, Koskinioti P, Gregoriou ME, Tsoumani KT, Bassiakos YC and Mathiopoulos KD, Housekeeping in Tephritid insects: the best gene choice for expression analyses in the medfly and the olive fly. Sci Rep-UK 7:1-9 (2017).

99 Malorny B, Hoorfar J, Bunge C and Helmuth R, Multicenter validation of the analytical accuracy of Salmonella PCR: towards an international standard. Appl Environ Microbiol 69:290-296 (2003).

100 Livak KJ and Schmittgen TD, Analysis of relative gene expression data using real-time quantitative $P C R$ and the 2(-Delta Delta $C(T)$ ) method. Methods 25:402-408 (2001). 